\title{
OUTCOME OF ANASTOMOTIC URETHROPLASTY: SINGLE-CENTER EXPERIENCE
}

\author{
MOHAMMAD SALAHUDDIN FARUQUE ${ }^{1}$, AKM ANWARUL ISLAM ${ }^{1}$, AKM KHURSHIDUL ALAM ${ }^{1}$, SELINA \\ RAHMAN ${ }^{2}$, FARUK HOSSAIN ${ }^{1}$
}

${ }^{1}$ Department of Urology, Bangabandhu Sheikh Mujib Medical University, Shahbag, Dhaka, ${ }^{2}$ Department Radiology \& Imaging, Module General Hospital, Dhaka, Bangladesh.

\begin{abstract}
Objective: To determine the short term outcome of anastomotic urethroplasty.

Material and Methods: From January 2013 to June 2015, 25 male patients underwent anastomotic urethroplasty at our center and were analyzed prospectively. Mean age was 28.1 years (range 13-50), average stricture length was $2.5 \mathrm{~cm}$ (range 1.5-2.5). Patients with post-prostatectomy stricture, stricture more than $2.5 \mathrm{~cm}$ in length or patients of stricture with neurogenic bladder and patients with any perineal disease were excluded from the study. Retrograde urethrogram and voiding cysto-urethrogram was done in every patient to assess stricture length and location. Stricture excision and end-to-end anastomosis of urethra with spatulation was performed in every patient. Minimum followup period was 6 months and maximum 30 months. All patients had obliterative stricture.
\end{abstract}

Results: The mean operative time was 105 min (range 90-120). Four patients (16\%) developed complications postoperatively. Wound infection occurred in 01 (04\%) patient. Stricture recurrence found in 02 (08\%) patients and erectile dysfunction in 01 (04\%) patients. Twenty one patients (84\%) had excellent outcome, Two (08\%) needed optical internal urethrotomy and of them one (04\%) failed to respond.

Conclusion: Anastomotic urethroplasty has a high success rate of $92 \%$. It is technically straightforward with minimal morbidity. Long term follow-up is strongly recommended for ultimate success.

Key words: Bulbo-prostatic anastomotic urethroplasty, Retrograde Urethrogram and Voiding Cysto-Urethrogram, Optical Internal Urethrotomy.

Bangladesh J. Urol. 2016; 19(1): 38-42

\section{Introduction:}

Urethral stricture is one of the oldest urological diseases, and its treatment remains a challenge for urologists[1]. Urethral stricture disease affects about 300 per 100000 men[2].

Trauma is a major cause of urethral disruption and stricture in the posterior urethra. Disruption of the prostato-membranous urethra occurs in approximately $(10 \%)$ of the patients with pelvic fractures, such injuries usually end up with stricture formation. Submucosal scars, has little effect on the diameter of the lumen, while dense scarring in the corpus spongiosum produces

Correspondence: Mohammad Salahuddin Faruque, Department of Urology, Bangabandhu Sheikh Mujib Medical University, Shahbag, Dhaka, Bangladesh, E-mail: faruque24th@gmail.com marked contracture of the lumen. The effect of superadded infection further worsens the condition[3].

It is important to differentiate between inflammatory or iatrogenic posterior urethral strictures and true pelvic fracture urethral distraction defects because they require entirely different surgical approaches. The term urethral stricture should be used to indicate a narrowing of the urethral continuity, such as sphincter strictures due to instrumentation or partial urethral tears. Urethral distraction defects have a gap between the two retracted and injured ends of the urethra, which is filled initially by the pelvic haematoma and later by fibrotic tissue[4].

In addition to appropriate initial management for urinary retention and associated injuries, careful selection of the operative technique and the experience of the 
urologist in urethral reconstructive surgery are crucially important for successful repair of post-traumatic urethral stricture. The decision as to which operative technique should be used is determined by various factors, including stricture length and location, situation of fractured pubic bone segments and the general health and age of the patient[5].

Treatment options are urinary diversion, dilatation of the urethra, endoscopic urethrotomy, and open surgical repair. Open surgical techniques include two main approaches: resection of the stricture with end-to-end anastomosis and substitution techniques by grafts or flaps, namely substitution urethroplasty[6]. The latter technique is often used for long strictures in which resection and anastomosis are not possible. Nearly all post-traumatic posterior urethral stricture in adults, can be corrected by one-stage transperineal end-to-end anastomotic urethroplasty. In adults, transperineal anastomotic urethroplasty is the treatment of choice for posterior urethral strictures secondary to direct or indirect pelvic trauma, which are usually located at the membranous urethra[5].

The timetable for the reconstruction of pelvic fracture urethral injuries is determined by the type and extent of associated injuries. If possible, it is desirable to proceed within 4 to 6 months after trauma[6].

We reviewed our experience and short term outcome of anastomotic urethroplasty in obliterative stricture disease.

\section{Patients and Methods:}

This prospective study was carried out on 25 patients admitted to Department of Urology, Bangabandhu Sheikh Mujib Medical University, Shahbag, Dhaka, Bangladesh from January 2013 to June 2015.

Patients of age $13-50$ years with completely obliterated post-traumatic stricture (blind stricture) of posterior urethra on retrograde urethrogram and Micturating Cystourethrogram (MCUG) measuring 1.5 to $2.5 \mathrm{~cm}$ were included in the study. Patients with postprostatectomy stricture, stricture $>2.5 \mathrm{~cm}$ in length or patients of stricture with neurogenic bladder or any perineal disease were excluded from the study. Also patients with pubic rami butterfly fracture which would obviously intervene the repair over, urinay bladder or rectal injury at the time of trauma were also excluded.

A total number of 25 patients who fulfilled the inclusion/ exclusion criteria were selected. Detailed history and physical examination of every patient was done. The investigations done before the procedure were complete blood count, Urine routine examination and culture, serum creatinine level, X-ray chest, screening for hepatitis $\mathrm{B}$ and $\mathrm{C}$ and abdominal ultrasonography. Retrograde urethrogram and voiding cystourethrogram was done in every patient to assess stricture length, location and caliber. After taking informed, written consent (explaining all the risks and complications of procedure), surgery was performed under general or spinal anaesthesia in all patients. After anaesthesia, patient was placed in exaggerated lithotomy position. An inverted "U" incision in the perineum was made. Incision was deepened to cut subcutaneous fat and bulbocavernous muscle in the midline to expose the bulbar urethra. Ametallic bougie was passed per urethra upto the stricture to facilitate the dissection. A window was created between the urethra and deeper structure, and urethra was dissected away from the corpora cavernosa distally upto penoscrotal junction so as to approximate the strictured segment.

Proximally dissection was carried upto the stricture and then more proximally approaching the normal part of urethra. Proximal urethra was approached with bougie from suprapubic cystostomy port, directed into urinary bladder neck and palpated perineally. With the help of suprapubic and urethral bougie stricture length was estimated. The affected urethral segment was extirpated,all the scar tissue was excised followed by bulboprostatic end-to-end anastomosis in which normal ends were spatulated and four to six interrupted sutures of $4 / 0$ polyglycolic acid (vicryl $4 / 0$ ) were applied over1216 Fr Foley's catheter. Suprapubic catheter was kept in situ. Haemostasis was secured and fascia and skin were closed in layers and dressing (T-bandage) was applied.

Intravenous antibiotics were administered for $48-72$ hours postoperatively and oral antibiotics were started thereafter. The patients were discharged on the 5th postoperative day, on average. Their urethral catheters were removed 3 weeks later after confirming anastomotic continuity by doing pericatheter urethrograme. Suprapubic catheter was removed one week later.

All the patients were followed up 06 monthly by a history, urinary flow rate estimate, retrograde urethrography and voiding cysto-urethrography when indicated. 
Results:

Age ranged from 13 to 50 years with mean age of 28.1 years.

The aetiology of the obliterative strictures were inflammation and trauma. Inflammatory strictures were Gonococcal in origin was in 04 patients $(16 \%)$ and traumatic strictures was in 21 patients (84\%), resulted from fall astride and road traffic accidents [Table-I].

Table-I

Aetiology of the stricture.

\begin{tabular}{lcc}
\hline Aetiology of stricture & $\begin{array}{c}\text { No. of patients } \\
(\mathrm{n} 25)\end{array}$ & Percentage \\
\hline Inflammatory & 04 & $16 \%$ \\
Traumatic & 21 & $84 \%$ \\
\hline
\end{tabular}

The length of strictured part was 1.5 to $2.5 \mathrm{~cm}$ with an average length of about $1.9 \mathrm{~cm}$. In all patients, stricture was excised and overlapping end-to-end anastomosis of urethra with good spatulation at healthy margins was performed. Operative time was between $90-120$ minutes. Blood transfusion was required in 10 (40\%) patients.

The postoperative complications are shown in Table II.

Table- II

Post operative complications.

\begin{tabular}{lcc}
\hline Complications & $\begin{array}{c}\text { No. of patients } \\
\text { (n 25) }\end{array}$ & Percentage \\
\hline Wound infection & 01 & $04 \%$ \\
Recurrence of stricture & 02 & $08 \%$ \\
Erectile dysfunction & 01 & $04 \%$ \\
\hline Total & 04 & $16 \%$ \\
\hline
\end{tabular}

There were early complications in one patient (04\%) and late complications in $03(12 \%)$ patients. Minimum follow up period was 06 months (range 06-30 months). Patients who developed symptoms during the follow up period were re evaluated by history, physical examination and radiological examination (retrograde Urethrogram). Recurrence was defined as symptomatic patients requiring additional treatment; Urethrotomy or other form of reconstruction.

In early complications, wound infection was found in 01 (04\%) patient which was managed conservatively. While in late complications, $02(08 \%)$ patients developed recurrent stricture at anastomotic site which was managed by optical internal urethrotomy. They were kept on clean intermittent self catheterization for few months. But one patient failed to void completely which was managed later by pubectomy and combined abdominoperineal approach. Erectile dysfunction was found in 01 (04\%) patients and treated by drugs. Overall 04 (16\%) patients developed complications postoperatively and initial success rate was $84 \%$. In terms of recurrence of stricture overall success rate was $92 \%$.

\section{Discussion:}

Injuries to the posterior urethra occur with pelvic fractures, mostly as a result of motor vehicle accidents. Injuries vary from simple stretching (25\%) to partial rupture (25\%) to complete disruption (50\%)[4].

In the majority of cases, pelvic fracture urethral injuries are not long, and the resultant obliteration is amenable to a technically straightforward mobilization of the corpus spongiosum with a primary anastomotic technique. The classic reconstruction consists of a spatulated anastomosis of the proximal anterior urethra to the apical prostatic urethra. Experience has demonstrated, however, that anastomosis of the proximal anterior urethra to any segment of the posterior urethra (apical, prostatic, or below) can be successfully accomplished by a widely spatulated anastomosis in which optimal epithelial apposition is achieved[6].

For the evaluation of stricture, retrograde urethrography (RUG) and voiding cystourethrography (VCUG) dynamic contrast imaging is the best approach despite the advent of newer imaging methods. Both studies were done to assess the stricture length and location[7].

After the introduction of optical system by Hopkins in 1960 and later Sachse in 1970, optical internal urethrotomy has been widely practiced. However, the results of different series raised doubt about the efficacy of this procedure and mentioned high recurrence rate approaching $80 \%$ in 5 years[8,9]. Optical internal urethrotomy is only curative for short stricture $(<1 \mathrm{~cm})$ that are not having significant spongiofibrosis especially with a thin channel of urethral lumen. Moreover, its role is very limited in the management of blind urethral stricture[8]. It was then in the second half of the twentieth century that urethroplasty, based on excision of the strictured area, and primary urethral anastomosis came into use again. Since then, new techniques such as skin, bladder urothelium, buccal mucosal free and 
pedicled grafts and expandable metal urethral splints have been developed[5].

Anastomotic perineal urethroplasty remains the gold standard with long-term success rates exceeding $90 \%[10]$. The key to successful anastomotic repair are adequate mobilization and tension-free spatulated anastomosis. The spatulation is important because if there is some contraction of the anastomosis after surgery, as would be expected, the caliber remains adequate[11]. The main limitation of this procedure is the length of stricture. If tried to bridge longer gap, it may result in ventral curvature of the penis, and the anastomosis will be under tension with risk of failure. For longer defects in which resection and anastomosis are not possible, substitution techniques by grafts or flaps (substitution urethroplasty) are used[12].

The age ranged in this study from 13 years to 50 years with mean age of 28.1 years. The results in this study confirm that patient age is not a factor in the success of procedure and end-to-end anastomosis should not be withheld from patients on the basis of age as observed by Barbagli et al[12].

The aetiology of urethral stricture has evolved over the years. In the past it was mainly associated with longstanding infectious disease (gonococcal urethritis) or trauma[13]. In the developed world, the aetiology of urethral stricture is mainly iatrogenic, such as transurethral resection, urethral catheterization, cystoscopy, prostatectomy, brachytherapy, hypospadias surgery and idiopathic $[14,15]$. In this study infection and trauma contributed $16 \%$ and $84 \%$ of the aetiology respectively.

An ideal urethral length for anastomotic urethroplasty is still debatable. Good results have been achieved by different investigators with length that range from $1 \mathrm{~cm}$ to $5 \mathrm{~cm}$. As a general rule, anastomotic urethroplasty is indicated in strictures $<1 \mathrm{~cm}$ long of the penile urethra and in strictures $<2 \mathrm{~cm}$ long of the bulbar urethra[4]. In this study, the length of strictured part was less than or equal to $2.5 \mathrm{~cm}$ with an average length of about $1.9 \mathrm{~cm}$, stricture was excised and end-to-end, spatulated, vascularized tension free anastomosis of urethra was performed.

Operative time was between $90-120$ minutes. Blood transfusion was required in 10 (40\%) patients.

Esteban-María et al., Gupta et al. and Hussain et al. reported wound infection in $4.0 \%, 3.6 \%$ and $2.5 \%$ of patient[5], while in this study, it was found in $01(04 \%)$ patient which was managed conservatively.
Incidence of recurrent stricture in this study was $08 \%$ while Dakum et al[16]. reported its incidence $34.4 \%$, Mundy et al[17]. $12 \%$, Tijani et al. ${ }^{18} 22.5 \%$ and Hussain et al[5]. $17.5 \%$ respectively. Recurrent strictures in present study was managed by optical internal urethrotomy. They were kept on clean intermittent self catheterization for few months. But one patient failed to void completely which was managed later by pubectomy and combined abdomino-perineal approach.

Choudhary AK et al[19]. and Hussain et al.[5] found Incidence of erectile dysfunction in $6.66 \%$ and $5.0 \%$ respectively. In this study, erectile dysfunction was found in $5.0 \%$. This low incidence is related to delayed repair which is recommended by most of the investigators.

So, in the present study 04 (16\%) patients developed overall complications postoperatively and initial success rate was $84 \%$. In terms of recurrence of stricture the success rate was $92 \%$ which is very much comparable to many previous studies.

\section{Conclusion:}

End-to-end anastomotic urethroplasty is an effective and durable approach to the post-traumatic posterior urethral stricture treatment. It is also the best available and gold standard procedure for traumatic posterior urethral strictures with the success rate of about $92 \%$. It is technically straightforward with minimal morbidity. Long term follow-up is strongly recommended for ultimate success.

\section{Conflict of Interest: None Declared}

\section{References:}

1. Fall B, Sow Y, Diallo Y, Sarr A, ZeondoC, Thiam A et al. Urethroplasty for male urethral strictures: Experience from a national teaching hospital in Senegal. African Journal of Urology, 2014;20:7681.

2. Jackson MJ, Sciberras J, Mangera A, et al. Defining a Patient-Reported Outcome Measure for Urethral Stricture Surgery. Eur Urol, 2011; 60(1):6068.

3. Sabah A, Al-Kadi, Safaa AM. Urethroplasty in posterior urethral injuries. Bas J Surg, 2006; 12:7679

4. Pineiro LM, Djakovic N, Plas E, Mor Y et al. EAU Guidelines on Urethral Trauma. European urology, 2010; 57:791-803.

5. Hussain A, Pansota MS, Rasool M, Tabassum SA, Ahmad I, Saleem MS. Outcome of end-to-end 
urethroplasty in post-traumatic stricture of posterior urethra. Journal of the College of Physicians and Surgeons Pakistan, 2013; 23(4): 272-275.

6. Jordan $\mathrm{GH}, \mathrm{McCammon} \mathrm{KA}$. Surgery of the Penis and Urethra. Kavoussi LR, Partin AW, Novick AC, Peters CA, editors. Campbell- Walsh Urology. 10th ed. Philadelphia: W.B. Saunders Company 2012.

7. Andrich DE, Mundy AR. What is the best technique for urethroplasty? Eur Urol, 2008; 54:1031-41.

8. Sandozi S, Ghazali S. Sachse optical urethrotomy, a modified technique: 6 years of experience. J Urol, 1988; 140: 968-9.

9. Charbit L, Mersel A, Beurton D, Cukier J. 5-year treatment results of urethral stenosis using internal urethrotomy in adults. Ann Urol, 1990; 24:66-7.

10. Levine J, Wessells $\mathrm{H}$. Comparison of open and endoscopic treatment of posttraumatic posterior urethral stricture. World J Surg, 2001; 25:1597601.

11. Mungadi IA, Mbibu NH. Current concepts in the management of anterior urethral strictures. Nigerian J Surg Res, 2006; 8:103-10.

12. Barbagli G, Angelis MD, Romano G, Lazzeri M. Long-term follow-up of bulbar end-to-end anastomosis: a retrospective analysis of 153 patients in a single center experience. J Urol, 2007; 178:2470-3.

13. Ofoha CG, Shu'aibu SI, Akpayak IC, Dakum NK, Ramyil VM. Anastomotic Urethroplasty for Short Segment Bulbar Urethral Stricture; Experience at the Jos University Teaching Hospital, Jos. IOSR Journal of Dental and Medical Sciences, 2015;14(1):01-05.

14. Fenton AS, Morey AF, Aviles R, Garcia CR. Anterior urethral strictures: etiology and characteristics. Urology, 2005; 65(6):1055-1058.

15. Lumen N, Hoebeke P, Willemsen P, De Troyer B, Pieters R, Oosterlinck W. Etiology of urethral stricture disease in the 21st century. J Urol. 2009; 182(3): 983-987.

16. Dakum NK, Ramyil VM, Amu CO. Outcome of urethroplasty for urethral stricture at Jos University Teaching Hospital. Niger J Clin Pract, 2008; 11: 300-4.

17. Mundy AR. Urethroplasty for posterior urethral strictures. BJU, 2003; 78:243-247.

18. Tijani KH, Ogo CN, Adeyomoye A. Excision and end-to-end anastomotic urethroplasty in the management of post-traumatic urethral stricture disease: experience and challenges in a Nigerian teaching hospital. Niger Postgrad Med J, 2010; 17:185-9.

19. Choudhary AK, MS, Jha NK. Is anastomotic urethroplasty is really superior than BMG augmented dorsal onlay urethroplasty in terms of outcomes and patient satisfaction: Our 4-year experience. Can Urol Assoc J, 2015;9(1-2):E22-6.

Abbreviations:

RGU : Retrograde urethrogram VCUG : Voiding cystourethrogram 